\title{
Testing Research of Hematite Concrete Beam Under Impact Loading
}

\author{
ZhenFu Chen ${ }^{1, a}$ JiaYuan Jiang ${ }^{1, b}$ YuanChu Gan ${ }^{1, c^{\star}}$ QiuWan Tao ${ }^{1, d}$ LongBin Li ${ }^{1, e}$ \\ 1.School of Urban Construction, University of South China Hengyang,Hunan 421001 \\ aemail: czf37@163.com; bemail:248798018@qq.com; \\ 'gan_yuanchu@126.com; dtaoqiuwan@163.com; $276557129 @ q q . c o m$
}

( ${ }^{*}$ Corresponding author )

Keywords: Drop-weight facility; Hematite concrete; Dynamic characteristics; Damage fracture Abstract. This study investigates the impact behavior of hematite concrete beams using dropweight facility. Reasonable experiment scheme is disigned, different tups were used and varying drop weights and heights were applied. This study measures impact loads, mid-spanaccelerations, and strains at the top and bottom edges of the beam. The time histories of impact force, the time histories of strain and the time histories of displacement are obtained.the destry whole pictures are obtained by high-speed photograph. When the strain rate ranges between $1.1 \mathrm{~s}^{-1}$ and $5.1 \mathrm{~s}^{-1}$, rate effect is significant.

\section{Introduction}

Radiations are found in nuclear power,industrial, medical, scientific research and other fields, It is a great threat to natural environment and human health .With the development of society, people gradually pay attention to the radiation problem[1]. Radiation protection concrete has a low cost, high reliability, wide application, and some other advantages. Thus they are widely applied to large radiation protection construction. While at present, for the study of the radiation protection concrete is still in the initial phase,and the research in dynamic characteristics is especially insufficient.

On account of the problem, in this study, hematite as the usually radiation protection material is selected to be aggregate. Eight groups of hematite concrete beam whose concrete mark is C25 and apparent density is $3600 \mathrm{~kg} / \mathrm{m}^{3}$ are designed. We have tested the dynamic properties of hematite concrete beam by utilizing drop-weight facility. The time histories of impact force, the time histories of strain, the time histories of displacement and some mech-anics parameters of hematite concrete are obtained.

\section{Specimen making and Apparatus}

Specimen making. This experiment adopts the hematite sand and stone wihch producted in HeBei, and the P.O 32.5 cement which producted in HengYang. According to the study of ChongMing $\mathrm{Wu}[2]$, we have designed the cube compressive strength $25 \mathrm{MPa}$, apparent density $3600 \mathrm{~kg} / \mathrm{m}^{3}$ and specimen size $100 \mathrm{X} 100 \mathrm{X} 400$ hematite concrete beams. Through the test debugging, finally the mix proportion is determined as follows:

water: cement: hematite sand: hematite stone $=0.63: 1: 3.58: 5.6$

After 28 days standard conservation, whose cube compressive strength of hematite concrete is measured to be $27.3 \mathrm{MPa}$, and apparent density is $2980 \mathrm{~kg} / \mathrm{m}^{3}$, which comply with the design requirements. 
Apparatus.Experiment apparatus are adopted as follows: the XJL-98 Drop-weight facility, drop hammers that range from $1 \mathrm{~kg}$ to $5 \mathrm{~kg}$ in weight and possesses a maximum drop height of $2 \mathrm{~m}$, dynamic signal analyzer, whose measurement sampling frequency is $96 \mathrm{~Hz}, \mathrm{DH} 5862$ programmable charge amplifier,the high-speed photograph,whose largest shooting frequency is one million frames per second.

\section{Data testing and Analysis}

According to the principle that changing the height and quality of drop hammer to design different conditions which can control the input energy and strain rate. The experiment adopts the same height of drop hammer $1.5 \mathrm{~m}$ and different quality respectively $1 \mathrm{~kg}, 2 \mathrm{~kg}, 3 \mathrm{~kg}, 4 \mathrm{~kg}$, and the same quality of drop hammer $3 \mathrm{~kg}$ and different height of $0.5 \mathrm{~m}, 1 \mathrm{~m}, 1.5 \mathrm{~m}, 2 \mathrm{~m}$ eight kinds of working conditions. For general, so as to not break universalityof the test, three pieces are selected for each working condition, the mean number is selected to analysis. After testing a variety of gasket material. We found that it's better to use plastic aluminum spacer, which demonstrates that the groups of test data are stable, whose deviation is tiny, it can achieve the stability of impact.

The momentum and impulse statistics.By data processing in a variety of drop hammer impactcond itions, the momentm and impulse statistics are shown in table 1, among them,the impulse is cal-culat ed by integraling the time histories of impact force. The momentum is calculated by some reas-onabl e assumptions that the hammer does freefall motion, ignores any air resistance and rebound, name ly $\mathrm{P}=\mathrm{m} \sqrt{2 \mathrm{gH}}\left(\mathrm{g}=9.8 \mathrm{~m} / \mathrm{s}^{2}\right)$. Analysis results show that the elastic impact conditions $(\mathrm{G} 151, \mathrm{Z} 305) \mathrm{due} \mathrm{t}$ $\mathrm{o}$ the impact energy is not enough, the hematite concrete beam remain in the dynamic elastic phase,

the momentum and impulse are approximate equal, which demonstrates that the impact proces $\mathrm{s}$ basic meet the theorem of momentum, whose energy is lossless. As for other six kinds of impact damage conditions, due to the input energy increased, fracture have been taken place. As it'sshow i $\mathrm{n}$ the table 1, with the input energy increased, the impulse loss increased, which indicates thatthe resi dual velocity of hammer is also increased. This conclusion can be proved from the falling speed o f hammer after the beam fractured.

Table 1 The momentum and impulse statistics under different impact working conditions

\begin{tabular}{|c|c|c|c|c|}
\hline $\begin{array}{c}\text { Working } \\
\text { conditions }\end{array}$ & $\begin{array}{c}\text { Mess } \\
\mathrm{m} / \mathrm{kg}\end{array}$ & $\begin{array}{c}\text { Height } \\
\mathrm{H} / \mathrm{m}\end{array}$ & $\begin{array}{c}\text { Impulse } \\
\mathrm{I} / \mathrm{N} \cdot \mathrm{s})\end{array}$ & $\begin{array}{c}\text { Momentum } \\
\mathrm{P} /(\mathrm{kg} \cdot \mathrm{m} / \mathrm{s})\end{array}$ \\
\hline $\mathrm{G} 151$ & 1 & 1.5 & 5.2 & 5.4 \\
\hline $\mathrm{G} 152$ & 2 & 1.5 & 10.2 & 10.8 \\
\hline $\mathrm{G} 153$ & 3 & 1.5 & 12.4 & 16.3 \\
\hline $\mathrm{G} 154$ & 4 & 1.5 & 14.3 & 21.7 \\
\hline Z305 & 3 & 0.5 & 9.1 & 9.4 \\
\hline Z310 & 3 & 1.0 & 10.6 & 13.3 \\
\hline Z315 & 3 & 1.5 & 12.3 & 16.3 \\
\hline Z320 & 3 & 2.0 & 13.8 & 18.8 \\
\hline
\end{tabular}


The time histories of impact force. The same height and different quality time histories of imp act force is shown in fig.1, the resultsshow that with the input energy increased, the peak loadincr eased, peak load presented,loading andunloading rate rised. In the working condition of G151the hematite concrete beam did not break, which occurs dynamic elastic impact, the relative impacttime is shorter, while the other three kindsof working conditions the beams are all breaked,the imp-act ti me became longer, the duration of theimpact time slightly imcresed, the response time, dischargetime is roughly the same. The same qua-lity and different height time histories of impact force is sh-own in fig.2, The results show that withthe input energy increased, the peak load increased, the worki ng condition of Z305 impact time is longer. Under the same quality, the other three kinds of workin $\mathrm{g}$ conditions whose impact response time is the same,peak load premised, impact time sligh-tly shor ter.

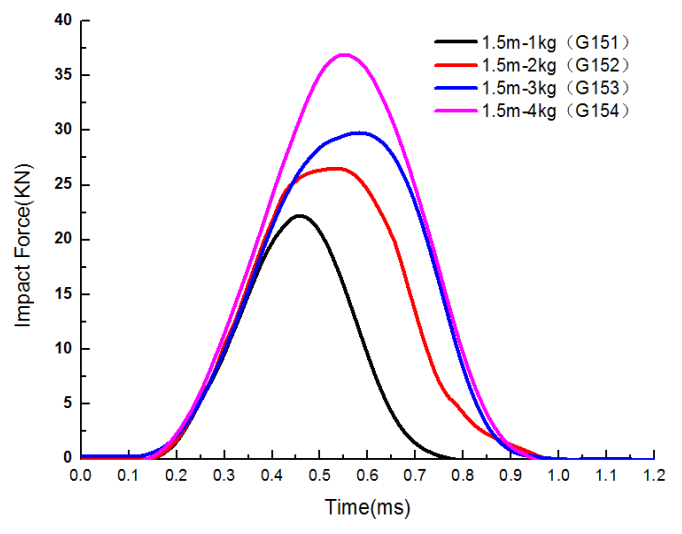

Fig.1 The same hight (1.5m) time histories of impact force

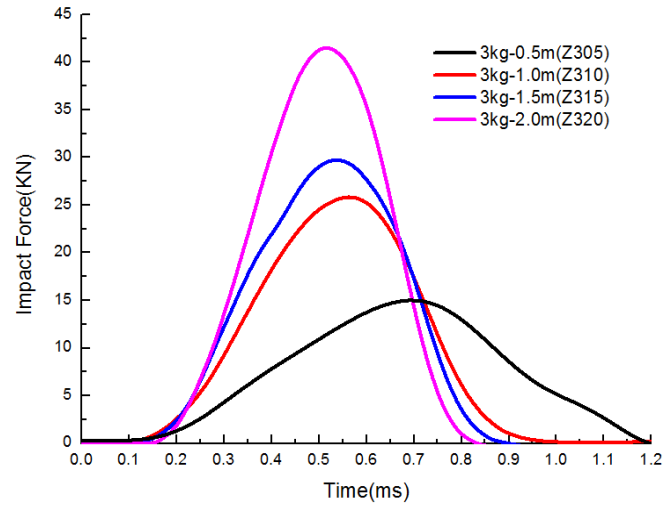

Fig. 2 The same quality $(3.0 \mathrm{~kg})$ time histories of impact force

The time histories of strain. Through setting up six longitudinal strain test point in the tension and compressive zone of the beam,the data is obtained after statistics. As for the same height of 1 . $5 \mathrm{~m}$ and the same quality of $3 \mathrm{~kg}$, whose time histories of strain is respectively shown in fig.3-4 (figu re in the tensile strain is negative).

The results show that the two kinds of elastic impact working condition (Z305, G151) both itst ensile and compressive strain are increased at present and then declined, finally there is a little ofr esidual deformation. In the impact fracture working conditions, the hematite concrete beam prod-u ced distortion under impact load, its tensile and compressive strain approximate symmetry beforede stroyed. With the load achieve the bending strength of tension zone the beam cracks, the tensilestr ain increased rapidly. In the porcess of fracture development, the compressive strain continue in-cre asing, finally when the crack developed through the beam, while the compressive strain decline.

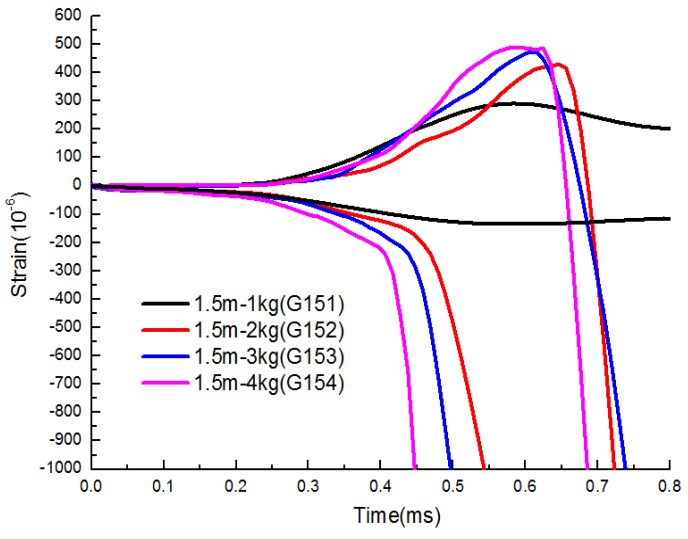

Fig.3 The same hight $(1.5 \mathrm{~m})$ time histories of strain

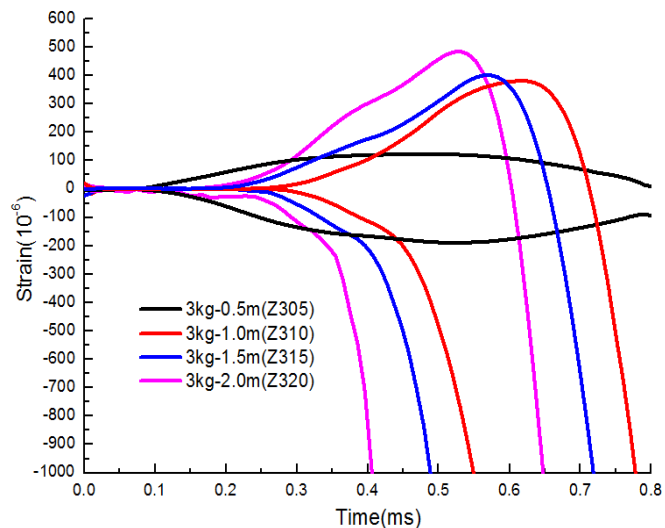

Fig.4 The same quality $(3.0 \mathrm{~kg})$ time histories of strain 
The time histories of displacement. The time histories of displacement is obtained by quadratic inte gration the acceleration time histories curve, the time histories of displacement is shown in fig.5 -6. Analysis results indicate that at the beginning, the elastic impact (G151,Z305)the displace-ment of beam increased and then declined, it is because of energy input, the cumulative displacementgrow to the maximum when the momentum tends to zero, and then the rigid spring back of beam caused by impact load which leads to thedecrease of displacement. Two reasons are explained why th e static displacement of beam is notequal to zero: $\AA$ the displacement generated by the static load of hammer itself $\mathcal{C}$ the micro cracks produced amount of damagewhich leads to the weaken-ing of $\mathrm{t}$ he bending stiffness and so residual displacement is left.The other six break conditions showthat wit $\mathrm{h}$ the input energy increased, the growth rate of displacement is increasd.

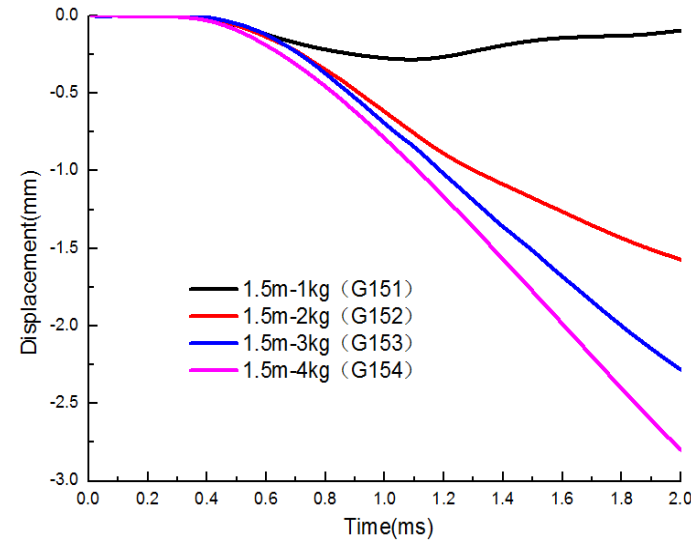

Fig.5 The same height $(1.5 \mathrm{~m})$ time histories of displacement

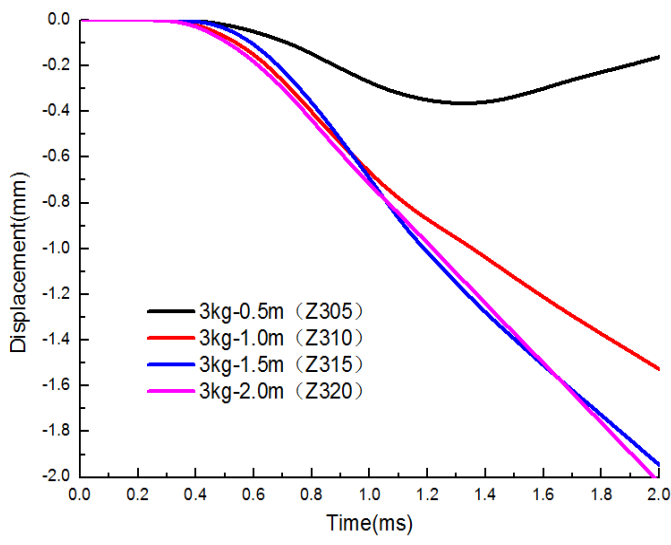

Fig.6 The same quality $(3.0 \mathrm{~kg})$ time histories of displacement

Fracture analysis. As for dynamic three-point bending of hematite concrete beam, the crack time, crack load and the ultimate tensile strain are important mechanical parameters which could meas ure its dynamic characteristics. Therefore, this paper trys to analysis the date of breakage bea-ms, in order to obtain the corresponding dynamic parameters. The strain mutation points are choosedto be break point of beam by taking a derivative with the time histories of strain, the derivative value of breakage point are choosed to be strain rate,.The analysis results are shown in table 2, all of the hematite concrete beam cracks at the moment of about $0.44 \mathrm{~ms}$, with the increase of the input energy the strain rate is increased, the ultimate tensile strain is at about 230 microstrain, the load of crack in creased, it demonstrates that the rate effect of the bending strength is significant.The dyna-mic incr ease factor(DIF) of hematite concrete demands further study.

Table 2 fracture analysis results

\begin{tabular}{|c|c|c|c|c|c|c|c|}
\hline $\begin{array}{c}\text { Working } \\
\text { conditions }\end{array}$ & $\begin{array}{c}\text { Mess } \\
\mathrm{m} / \mathrm{kg}\end{array}$ & $\begin{array}{c}\text { Height } \\
\mathrm{h} / \mathrm{m}\end{array}$ & $\begin{array}{c}\text { Peak load } \\
\text { Pmax/KN }\end{array}$ & $\begin{array}{c}\text { Crack timeT } \\
\text { c/ms }\end{array}$ & $\begin{array}{c}\text { Crack load } \\
\text { Pc/KN }\end{array}$ & $\begin{array}{c}\text { ultimate tensile } \\
\text { strain } \\
\mathbf{\varepsilon} / 10^{-6}\end{array}$ & $\begin{array}{c}\text { strain rate } \\
\boldsymbol{\varepsilon} / \mathbf{s}^{-1}\end{array}$ \\
\hline $\mathrm{G} 152$ & $2 \mathrm{~kg}$ & $1.5 \mathrm{~m}$ & 26.5 & 0.46 & 24.4 & 185 & 1.1 \\
\hline $\mathrm{G} 153$ & $3 \mathrm{~kg}$ & $1.5 \mathrm{~m}$ & 29.8 & 0.44 & 25.3 & 237 & 3.6 \\
\hline $\mathrm{G} 154$ & $4 \mathrm{~kg}$ & $1.5 \mathrm{~m}$ & 37.0 & 0.42 & 31.2 & 248 & 4.5 \\
\hline $\mathrm{Z} 310$ & $3 \mathrm{~kg}$ & $1.0 \mathrm{~m}$ & 25.9 & 0.45 & 21.1 & 196 & 2.2 \\
\hline $\mathrm{Z} 315$ & $3 \mathrm{~kg}$ & $1.5 \mathrm{~m}$ & 29.7 & 0.43 & 24.2 & 229 & 3.7 \\
\hline $\mathrm{Z} 320$ & $3 \mathrm{~kg}$ & $2.0 \mathrm{~m}$ & 41.5 & 0.40 & 32.6 & 257 & 5.1 \\
\hline
\end{tabular}

The crack phase,crack extension phase,crack through phase images are obtained by using highspeed photograph to trace the fracture process of working condition Z320. As is shown in the 
figure7-9, cracks are marked with the yellow line.To compare the three pictures, the development of cracks process can be observed from the stage of crack phase (about $0.4 \mathrm{~ms}$ ) to crack through phase (about $0.50 \mathrm{~ms}$ ), which shows the whole process of fracture happened at extremely short time(about $0.10 \mathrm{~ms})$.

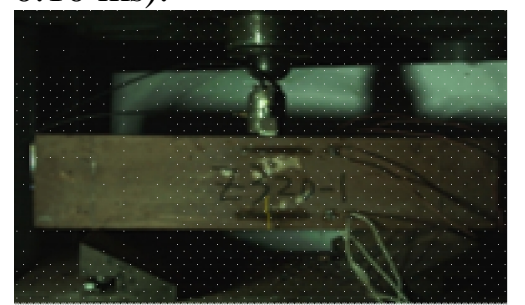

Fig.7 Crack phase

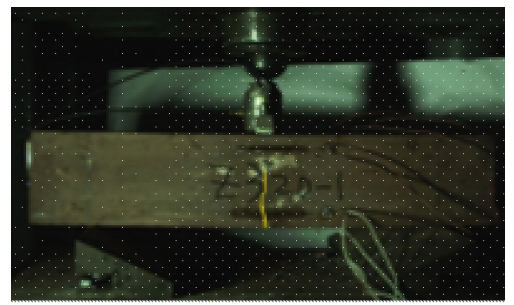

Fig. 8 Crack extension phase

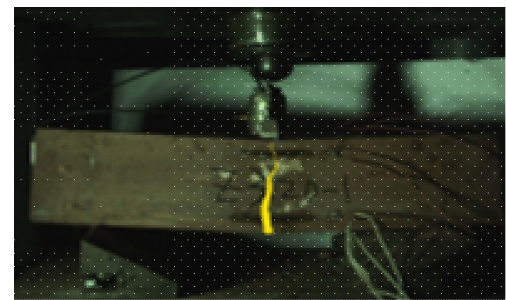

Fig.9 Crack through phase

\section{Conclusions}

The test that the weight and height of hammer respectively $3 \mathrm{~kg}, 0.5 \mathrm{~m} \mathrm{(Z305),} \mathrm{and} \mathrm{the} \mathrm{weightand}$ height of hammer respectively $1 \mathrm{~kg}, 1.5 \mathrm{~m}$ (G151)on hematite concrete beams which under thecond ition of impact load is accomplished. The repeatability of the two dynamic elastic impact pro-cess $i$ $\mathrm{s}$ stable,the time histories of impact force, displacement and strain are obtained. The analysis result $s$ indicates that there are initial microcracks in the end of impact which caused certain damage on the beam, and then leads to rigidity weakening and tiny residual deformation.

The working conditions that in the same quality $(3.0 \mathrm{~kg})$ and different hight under the im-pact load which tested in the hematite concrete beam, whose strain rate ranged from 1.1 to $4.5 \mathrm{~s}^{-1}$ area ccomplished. The dynamic failure process and some correlative time histories are obtained. The results show that with the drop height of hammer increased, the duration of impact becomeshort er,the strain rate increased, the peak load increasd and advanced.

The working conditions that in the same height $(1.5 \mathrm{~m})$ and different quality under the impact load which tested in the hematite concrete beam, whose strain rate ranged from 2.2 to $5.1 \mathrm{~s}^{-1}$ are accomplished. The results show that due to the same impact velocity, the impact growth rate is basic similar in the early, with the increase of quality, the impact time slightly imcresed, the peak load increased.

Several dynamic parameters of beam are obtained by analyzing the six group cracked hematite concrete beam which under the impact load.The analysis results show that at the all working conditions, with the input energy increased, the strain rate increased,the crack moment of beams is happaned at about $0.44 \mathrm{~ms}$, and the ultimate tensile strain is happened at about 230 microstrain,the crack load increased, the hematite concrete beam shows a obvious rate effect at the flexural strength.

\section{References}

[1] ZhiSheng Pan Radiation protection concrete research present situation, problems and development trend [J]. Journal of wuhan university of technology 2011,01:45-51.(In Chinese)

[2] ChongMing Wu. The experimental study of intense radiation shielding concrete. Nuclear engineering [D]. Central south university, 2008.(In Chinese)

[3] Min Li. Material rate correlation effect on dynamic performance of reinforced concrete structures [D] DaLian university of technology, 2011.(In Chinese)

[4] Bin $\mathrm{Xu}$, Xiang Ceng. Reinforced concrete beam under the impact load performance testing research [J]. Journal of civil engineering, 2014, 11:41-51+61.(In Chinese)

[5] XinYu Liang, FaNing Dang,Wei Tian,HouQun Chen . Different loading rate on the dynamic characteristics of the concrete specimen impact study [J]. Journal of Hydroelectric Engineering,2009 ,05:35-40. (In Chinese) 